\title{
Correction
}

\section{Correction to: Neuroendocrine characteristics of induced pluripotent stem cells from polycystic ovary syndrome women}

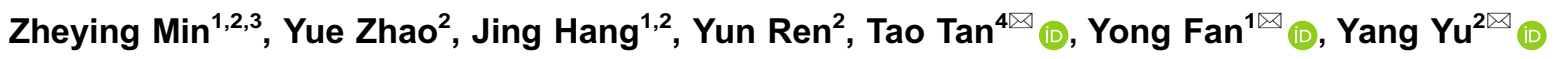 \\ ${ }^{1}$ Key Laboratory for Major Obstetric Diseases of Guangdong Province, The Third Affiliated Hospital of Guangzhou Medical \\ University, Guangzhou 510150, China \\ ${ }^{2}$ Beijing Key Laboratory of Reproductive Endocrinology and Assisted Reproductive Technology and Key Laboratory of \\ Assisted Reproduction, Ministry of Education, Center for Reproductive Medicine, Department of Obstetrics and Gynecology, \\ Peking University Third Hospital, Beijing 100191, China \\ ${ }^{3}$ Peking-Tsinghua Center for Life Sciences, Academy for Advanced Interdisciplinery Studies, Peking University, Beijing \\ 100871, China \\ ${ }^{4}$ Yunnan Key Laboratory of Primate Biomedical Research, Institute of Primate Translational Medicine, Kunming University of \\ Science and Technology, Kunming 650500, China \\ $凶$ Correspondence: tant@Ipbr.cn (T. Tan), yongfan011@gzhmu.edu.cn (Y. Fan), yuyang5012@hotmail.com (Y. Yu)
}

\section{CORRECTION TO:}

\section{PROTEIN CELL 2019, 10(7):526-532 \\ HTTPS://DOI.ORG/10.1007/S13238-018-0600-1}

In the original publication the Fig. 2 and the Supplementary Material 1 was incorrect. The correct version of Fig. 2 and the Supplementary Material are provided in this correction article.

NESTIN should be corrected to PAX6 in Fig. $2 \mathrm{C}$ legend and at page 528 and Supplementary Material 1. NANOG should be corrected to PAX6 in Fig. $2 \mathrm{C}$ picture.

\section{OPEN ACCESS}

This article is distributed under the terms of the Creative Commons Attribution 4.0 International License (http://creativecommons.org/ licenses/by/4.0/), which permits unrestricted use, distribution, and reproduction in any medium, provided you give appropriate credit to the original author(s) and the source, provide a link to the Creative Commons license, and indicate if changes were made.

The original article can be found online at https://doi.org/10.1007/ s13238-018-0600-1.

Electronic supplementary material The online version of this article (https://doi.org/10.1007/s13238-019-00664-y) contains supplementary material, which is available to authorized users. 


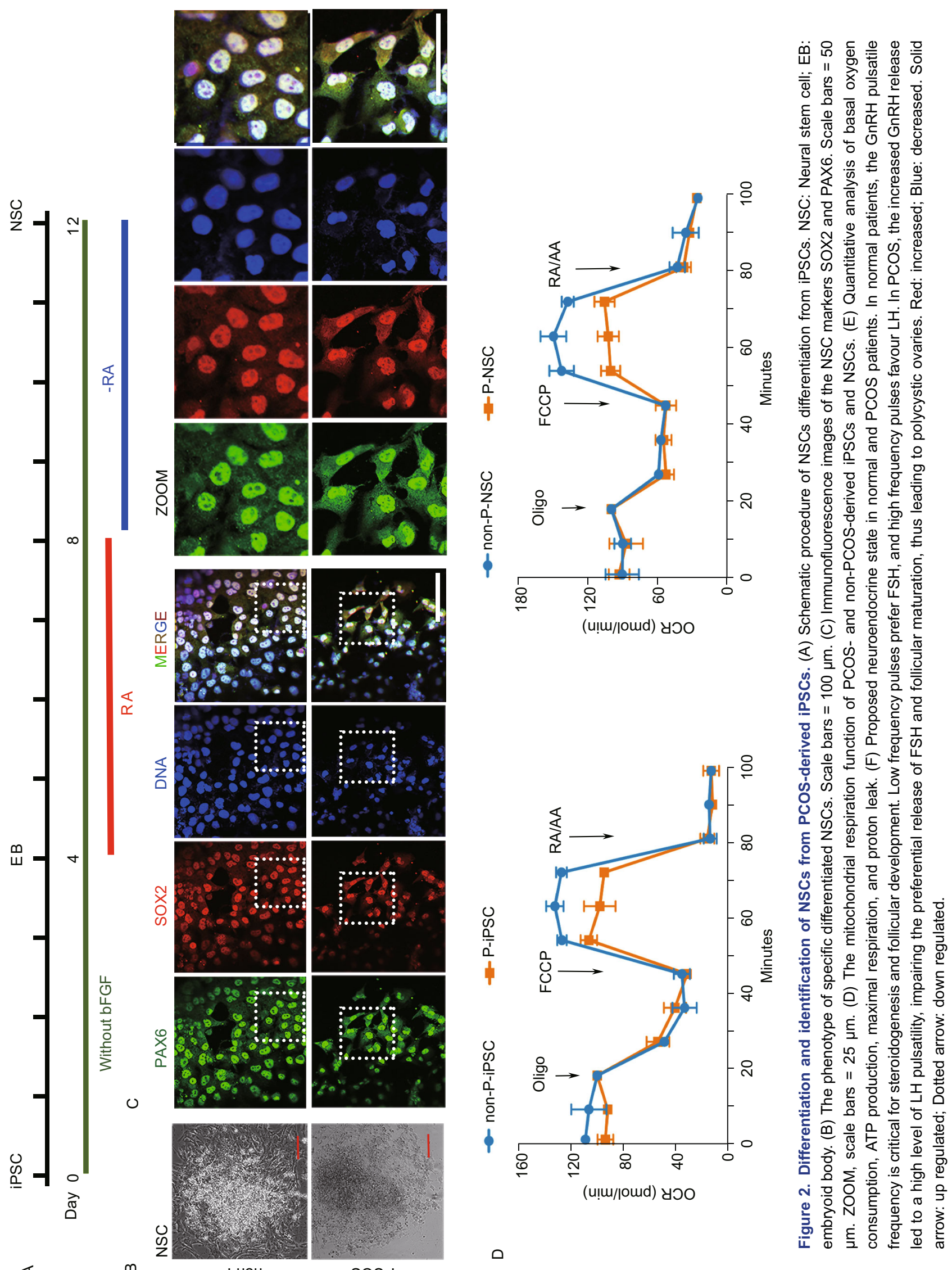



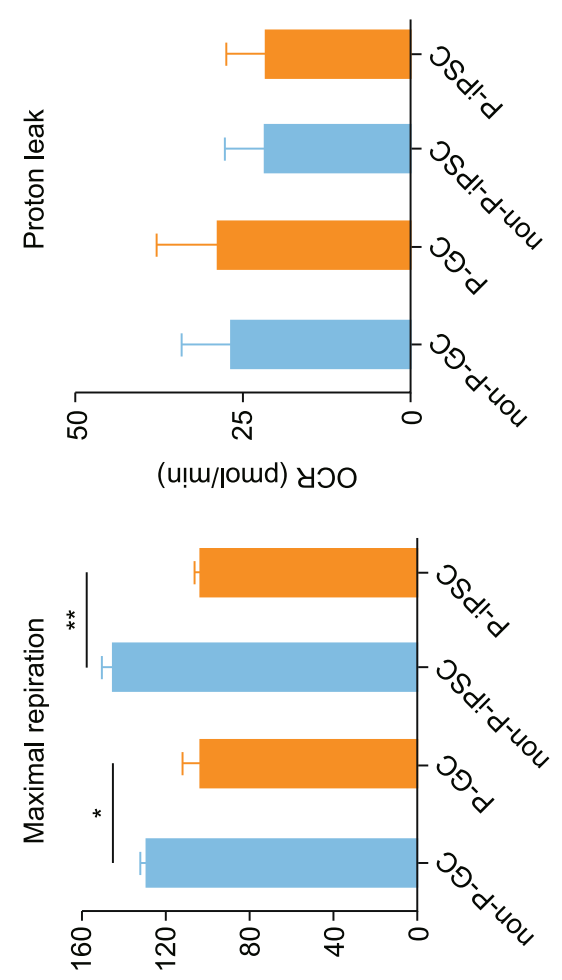

(u!m/|oud) yว०
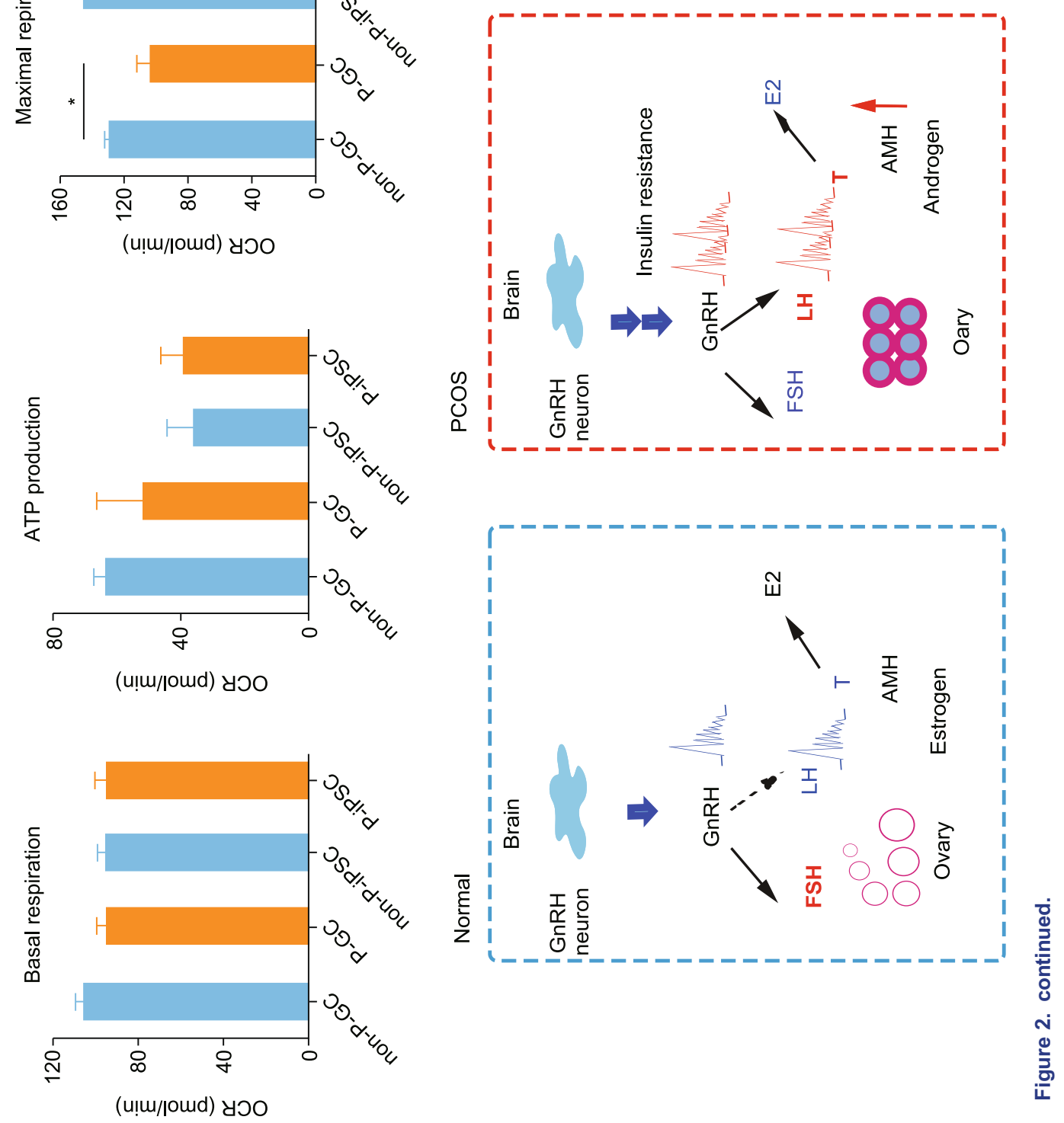

ш

丩 